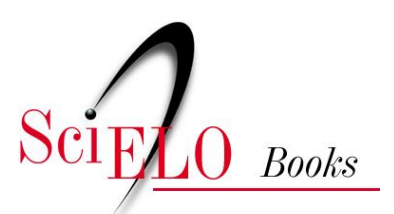

\title{
Seduepb
}

\section{As estratégias da Secom/PR e a construção de uma identidade brasileira no âmbito internacional}

\author{
Silvia Garcia Nogueira
}

\section{SciELO Books / SciELO Livros / SciELO Libros}

NOGUEIRA, SG. As estratégias da Secom/PR e a construção de uma identidade brasileira no âmbito internacional. In: TRAVANCAS, I., and NOGUEIRA, SG., orgs. Antropologia da comunicação de massa [online]. Campina Grande: EDUEPB, 2016. Paradigmas da Comunicação collection, pp. 283-

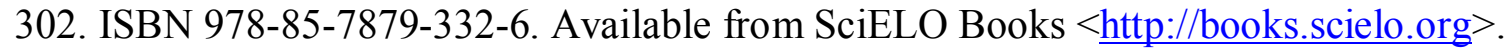

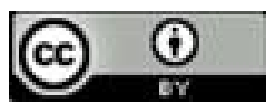

All the contents of this work, except where otherwise noted, is licensed under a Creative Commons Attribution $\underline{4.0 \text { International license. }}$

Todo o conteúdo deste trabalho, exceto quando houver ressalva, é publicado sob a licença Creative Commons Atribição 4.0. 


\section{As estratégias da Secom/PR e a construção de uma identidade brasileira no âmbito internacional}

Silvia Garcia Nogueira

Participar da "sociedade do espetáculo" atual implica em fazer o jogo social da exposição midiática, cuja principal meta é tornar-se visível. Não se trata da busca pela visibilidade em si, mas de uma administração de visibilidade diante dos outros, como analisada por Thompson (1998), na qual os jogadores tentam controlar o que e o modo como algo será dado a conhecer. Ou, nas palavras do autor, trata-se de um contínuo processo de "tomada de decisões sobre o que, a quem e como se pode tornar público” (p.125).

Tais tomadas de decisão costumam levar em consideração benefícios e riscos para o grupo que a exposição pública poderá trazer. Entre os riscos, o principal é o da perda de controle sobre a construção da imagem de si desejada, que em geral culmina na produção de um "escândalo". Este, na análise de Thompson (1998, p.130), "é um risco profissional da política na era da visibilidade mediada”. 
Tendo essa discussão como pano de fundo neste trabalho, pretende-se apresentar e analisar as estratégias utilizadas pela Secretaria de Comunicação da Presidência da República para a produção de informações sobre o "Brasil", direcionadas a formadores de opinião pública mundial, com o objetivo de influenciar as percepções do país no âmbito internacional.

Para isso, tendo como fonte uma pesquisa intitulada "A Construção Estratégica de Imagens do Brasil no Exterior: Comunicação Internacional e Política Externa na ótica da SECOM/ Presidência da República" (2010-2012) ${ }^{98}$, com apoio financeiro do $\mathrm{CNPq}$, utilizar-se-ão abordagens tanto do campo da Antropologia da Comunicação quanto das Relações Internacionais.

Trata-se, em especial, de tentar discutir que "Brasil" é esse apresentado atualmente na ótica do governo brasileiro e as dimensões políticas e culturais estratégicas presentes nesse jogo em que a utilização dos meios de comunicação de massa desempenha papel central.

\section{Opinião pública, identidade (Inter) nacional e política externa}

Os papéis desempenhados pela mídia e pela opinião pública nas relações internacionais vêm ganhando destaque no campo da Comunicação Internacional, particularmente no que se refere a sua influência em formulações de políticas externas, ao construir um ambiente social em que tais políticas são elaboradas e empreendidas.

98 Gostaria de agradecer aos profissionais da Secom/PR, incluindo-se aí a CDN, a Área Internacional e a Comunicação Pública, e especialmente a Rodrigo de Lima Baena Soares, Augusto Pestana, Jorge Duarte e Maysa Provedello, por gentilmente me atenderem e fornecerem informações preciosas para esta pesquisa. Agradeço, ainda, ao CNPq por ter apoiado financeiramente a pesquisa, viabilizando sua realização. 
Assim, os discursos midiáticos, políticos, diplomáticos, empresariais, militares e acadêmicos são essenciais na construção de representações coletivas internas e externas sobre um Estado, e a identidade nacional a ele relacionado.

Como observado por Faria (2008), sobre a relação entre opinião pública e a Política Externa Brasileira (PEB), apesar da tendência tradicional ao insulamento da formulação da política externa do país no Executivo - seguindo um padrão top down atualmente há uma "maior porosidade do processo de produção da PEB” (p.84), com a participação de novos atores, produzindo um efeito bottom up (p.85) ${ }^{99}$.

Quando o assunto é opinião pública, contudo, nem sua compreensão conceitual nem a dimensão concreta que o termo carrega são isentas de múltiplas compreensões. Para alguns, como Bourdieu (1982; 1997), cabe a pergunta se de fato ela existe ou trata-se de uma abstração. Já para Champagne (1990), trata-se de um jogo político do qual fazem parte especialistas que alimentam e constroem a crença de um povo, particularmente por meio da aplicação de pesquisas de opinião. Como lembra Scotto (2003), ambos acreditam que nos regimes democráticos, a opinião pública corresponde a um espaço social dominado por profissionais da política que disputam a definição do próprio termo.

99 Isso significa o entendimento de que outros atores sociais - como ONGs, movimentos sociais, imprensa, opinião pública, etc. - passaram a influenciar de baixo para cima (bottom up) a formulação no campo da Política Externa Brasileira, já que começaram a se interessar e a ter mais acesso aos assuntos relacionados ao campo internacional. Antes, o tema da PEB restringia-se basicamente ao Executivo e demais agentes governamentais a ele relacionados, tendo sua formulação caracterizada pela direção do tipo cima para baixo (top down), ou seja, com a formulação da PEB pelo Executivo e sem participação de outros atores sociais nesse processo. 
Ainda para Champagne (1990), nas sociedades democráticas, a "opinião pública", relacionada às elites políticas até o início do século XX, passa a ser substituída por outra "opinião pública", esta produto espontâneo dos movimentos de massa e das manifestações das ruas.

No que se refere ao que poderia ser chamado de "opinião pública mundial”, Ekekrantz (2006, p.97) ressalta que se trata de um fenômeno de "dupla face":

Primeiro, trata-se de uma construção ou projeção baseada nas necessidades legítimas, nas percepções da realidade conduzidas pela mídia, e, às vezes, media panics, entre várias elites. $\mathrm{Ou}$ melhor, opinião pública projetada de cima. Segundo, há opinião pública no sentido clássico, de baixo, isto é, para não ser associada a dados gerados pelas pesquisas de opinião. (EKEKRANTZ, 2006, p. 97).

Então, de acordo com Champagne e Ekekrantz, está embutido no próprio conceito o duplo entendimento de que tanto pode relacionar-se às elites quanto às "manifestações de rua". E, nesse sentido, fica mais claro perceber a dimensão política estratégica em torno da própria definição do que seja "a" ou "uma" opinião pública, para os agentes que integram tal disputa discursiva.

Cabe observar que o conceito adotado aqui de opinião pública é o mesmo utilizado por Manzur (1999, p.30), ou seja, um "conjunto das correntes de pensamento expressas em um país em um determinado período". A autora aponta, também, a relevância do papel desempenhado pela imprensa - que simultaneamente reflete e induz a formação de opiniões e tendências - para a construção desse conceito (p.31). 
Embora entendendo ainda que a definição da autora implica em um grande nível de abstração, é justamente por ser pouco preciso que acreditamos que ela só pode ser definida em ato, sendo construída a partir dos discursos dos agentes que falam em seu nome e referidos a situações concretas. Assim, para alguns, a opinião pública é percebida por meio de pesquisas de opinião (enquetes); para outros, por um imaginário relativamente compartilhado em relação a um assunto; e, para outros ainda, pode ser apreendida por tendências de comportamentos e práticas sociais observáveis.

De qualquer modo, perpassando a construção de um espaço social de influência sobre tais tendências e comportamentos sociais compartilhados, está a produção da visibilidade midiática em torno de assuntos e questões de interesse de diversos agentes. Isso porque, como analisado por Weber (2006, p.118), que chama a atenção para a dimensão de cálculo político - embora esta seja uma interpretação nossa - estão incluídos na visibilidade gerada pela mídia,

os votos e a formação da imagem pública, com
todas as suas consequências controladas por atuan-
tes assessorias. As relações e interesses entre política
e meios de comunicação de massa produzem uma
perversa interdependência e salutar infidelidade,
em que os interesses sociais e a ética podem ser
defendidos ou driblados, dependendo da audiência
ou do futuro da nação. (WEBER, 2006, p.118).

A interpretação da autora, assim, está em consonância com a dimensão política profissional que envolve a questão da opinião pública em sentido empírico, tal como abordado por Scotto. Para Weber (2006, p.127), "a política tem meios e investimentos sofisticados para se comunicar, para obter visibilidade, mas é no espaço público da mídia que essa visibilidade provoca credibilidade”. 
Entretanto, o espaço de visibilidade é disputado e o sucesso de sua ocupação depende de vários aspectos, segundo Weber (2006, p.132):

A natureza da instituição em relação aos interesses sociais, políticos e econômicos; estabelecimento de ações e relações com os media; a concepção estratégica da comunicação e a utilização de meios adequados a exigências e expectativas dos públicos-alvos, assim como em relação à opinião pública. Weber (2006, p.132).

A conexão entre visibilidade e credibilidade dependeria, no entanto, de ações comunicativas que envolvam a decodificação de informações:

Todas as informações (jornalísticas e publicitárias) deverão ser passíveis de decodificação, desde a sugestão de pautas para mídia impressa e eletrônica, logomarcas, peças publicitárias, material audiovisual, espaços internéticos, eventos, viagens, premiações, espetáculos, protocolos públicos até o discurso. A visibilidade deve deixar marcas, pistas atratoras para a formação da imagem pública favorável. (WEBER, 2006, p.132).

Como será visto adiante, a Secom/PR utiliza grande parte de tais recursos, listados por Weber, para participar do dinâmico processo de produção de códigos compartilhados para fins de formação de imagem pública favorável. Neste caso, na construção de uma percepção positiva de "Brasil".

Cabe observar, em consonância com Hall (2006, p.50-51), que "as culturas nacionais são compostas não apenas de instituições culturais, mas também de símbolos e representações". Como 
um discurso - "um modo de construir sentidos que influencia e organiza tanto nossas ações quanto a concepção que temos de nós mesmos" (p.51) - as culturas nacionais produzem sentidos sobre "a nação", com os quais nos identificamos.

Tais identificações no período em que vivemos - como "habitantes do líquido mundo moderno", conforme Bauman (2005, p.32) - são caracterizadas como "identidades em movimento". Assim, a Secom/PR utiliza recursos de distintas naturezas para ocupar um bom espaço de visibilidade e alcançar uma imagem positiva na construção de percepção política sobre quem o "Brasil é". Para isso, se por um lado lança mão das novas tecnologias e das mídias sociais para atingir públicos diversos, por outro, trabalha com uma ideia resiliente de identidade nacional.

\section{A Secom/Presidência da República}

A Secretaria de Comunicação Social da Presidência da República (Secom/PR), segundo Duarte (2012), divide-se em duas grandes esferas de atuação: 1) Imprensa e Porta-Voz (Presidência); 2) Comunicação Institucional (Executivo e Presidência).

Os profissionais envolvidos na primeira, que trabalham diretamente ligados à Presidência da República, atuam nos seguintes segmentos: Imprensa Nacional, Imprensa Regional, Imprensa Internacional, Monitoramento e Análise da Mídia de Comunicação, Blog do Planalto, além do Porta-Voz da Presidência.

Já na Comunicação Institucional, os profissionais dedicamse aos setores de Comunicação Pública, Comunicação para o Exterior, Internet, Planejamento, Patrocínio, Norma, Comunicação Integrada (Publicidade), Eventos.

Cabe ressaltar, conforme Jorge Duarte, coordenador do Núcleo de Comunicação Pública, em entrevista à autora (em 
08/05/2012), que se trata de uma divisão informal, baseada principalmente em uma distribuição de tarefas. O jornalista ressalta, ainda, que na Secom/PR, trabalham jornalistas, diplomatas, advogados, entre outros profissionais, e que para fazer parte do quadro a principal característica é "entender de comunicação".

Embora as funções no geral sejam preestabelecidas, há cotidianamente uma integração forte entre os profissionais da Secom/ PR. Além de executarem trabalhos conjuntos, coordenados e complementares em nível interno à própria secretaria, estão constantemente conectados a 262 órgãos - que incluem ministérios, Banco Central, Caixa Econômica, Ibama, escolas técnicas e universidades, entre outros - por meio do Sistema de Comunicação do Poder Executivo Federal (Sicom).

No que se refere à comunicação externa no âmbito internacional, foi precisamente para "promover o Brasil e a sociedade brasileira no exterior" ${ }^{100}$ que se criou em 2009, na Secom/PR, a "Área Internacional". De acordo com a própria apresentação exposta em seu site, "o que se busca é, por meio de um trabalho persistente e de longo prazo, promover o país, sua identidade, sua diversidade e suas potencialidades. A mensagem se centra na confiabilidade e na estabilidade do país" ${ }^{101}$.

Desenvolvendo um trabalho coordenado com alguns órgãos públicos e, eventualmente, com a iniciativa privada, o foco da Área Internacional (AI) da Secom/PR recai, do ponto de vista estratégico,

100 Citação retirada do site da Secretaria de Comunicação Social da Presidência da República, no item "Atribuições”, postada em: 09/11/2009 (http://www.secom.org. br). Em 2012, o site estava passando por uma reformulação. Neste caso, optou-se por trabalhar pelo que era divulgado no período de sua criação.

101 Citação retirada do site da Secretaria de Comunicação Social da Presidência da República, no item "Atribuições", postada em: 09/11/2009 (http://www.secom.org. br). 
sobre quatro eixos temáticos (denominados pela secretaria como "temas estratégicos"), que norteiam o desenvolvimento de suas atividades: "Economia", "Estabilidade Político-Institucional", "Inclusão Social" e "Meio Ambiente"102. O lema de campanha da Secom/PR, conforme explicitado em seu site103, é: "Estamos vivendo um novo Brasil. Feito por você. Respeitado pelo mundo". O objetivo é a divulgação das transformações positivas pelas quais o país passou, nos últimos anos, dentro de um "processo de crescimento econômico sustentado com desenvolvimento social”.

Os desafios aos quais estão submetidos, segundo a Secretaria, são: 1) sensibilizar para o novo patamar de desenvolvimento atingido pelo país, fortalecendo a autoestima da população; 2) demonstrar que os avanços econômicos e sociais estão presentes no dia a dia da população e refletem em vários indicadores; 3 ) destacar que o processo de construção de um país melhor continua em andamento e que é preciso se preparar para desafios ainda maiores.

Tais metas inserem-se em uma dimensão estratégica em que a divulgação de informações nos níveis doméstico e internacional ocupa na formação de uma imagem - para dentro e para fora - de quem "è" o Brasil e nas políticas implementadas a partir dessa identidade nacional construída ${ }^{104}$.

Em termos concretos, uma série de ações vem sendo empreendida nesse sentido. Entre elas, uma importante foi a realização de uma licitação, em 2008, para a contratação de uma empresa que

102 Id.,ibid

103 Id.,ibid.

104 Cabe ressaltar que a construção da imagem de uma identidade nacional quando aliada a um enfoque carregado de intenções políticas funciona como um importante capital simbólico - no sentido bourdiano do termo - que produz impactos concretos na relação de um estado com outros no âmbito internacional. 
cuidasse da divulgação do país no exterior, na qual saiu vencedora a $\mathrm{CDN}$, com um contrato de 15 milhões.

Criada em 2009, a CDN International Inc., com sede em Washington, D.C., e trabalhando com a empresa Fleishman-Hilard, é a empresa do Grupo CDN responsável por ações de comunicação corporativa nos Estados Unidos. Assim, ela desenvolve atividades de planejamento, coordenação e suporte nas áreas de assessoria de imprensa e comunicação, relações públicas e relações institucionais, objetivando criar ou fortalecer seu relacionamento com os mercados brasileiro e americano (fonte: http://www.grupocdn.com.br).

A Área Internacional da Secom/PR é formada basicamente por jornalistas da própria Secretaria, diplomatas de carreira e jornalistas da CDN. Paralelamente, ocorre ainda uma conexão com outro setor da Secom/PR, o de Comunicação Pública, mais direcionado à comunicação doméstica, ao público brasileiro. Nele, trabalham jornalistas e outros profissionais que "entendam de comunicação", segundo o coordenador do Núcleo de Comunicação Pública, Jorge Duarte.

Cabe observar que, de acordo com os que lá desempenham suas atividades, o diálogo estreito entre os envolvidos no trabalho de comunicação governamental se tornou possível na medida em que ocorreu uma mudança da política de comunicação antes fragmentada para uma percepção de que a comunicação produzida pelo governo deveria ser unificada e integrada.

Em palestra intitulada "Comunicação Social", proferida no Ciclo de Palestras da Secretaria de Assuntos Estratégicos (SAE) da Presidência da República (em 2 de setembro de 2010), o então Ministro da Secretaria de Comunicação Social da Presidência da República, Franklin Martins (2010), apresenta sua visão sobre o tema, particularmente sobre o modo como o governo trata do assunto no período compreendido entre 2007 e 2010, mas que 
podemos considerar ainda válidos pelo atual governo da presidenta Dilma Roussef.

Segundo o ministro, nesse período o governo seguiu sete princípios: 1) a comunicação deve ser integrada, de modo que o governo não produza mensagens contraditórias, já que deve compartilhar uma mesma linguagem; 2) a relação com a imprensa deve se constituir como o eixo da comunicação do governo e não a propaganda; 3) a liberdade de imprensa, uma conquista social, inclui a possibilidade de que o trabalho jornalístico deva ser criticado ou corrigido quando erra ou desinforma a população; 4) existem várias imprensas com características e necessidades distintas; 5) a publicidade do governo deve obedecer a parâmetros "técnicos, claros, transparentes, acessáveis por todos” (MARTINS, 2010, p.8); 6) nas relações com os meios de comunicação, deve haver "profissionalismo", "transparência" e "fluidez"; 7) a comunicação deve ser institucionalizada, a partir da criação de instrumentos que permaneçam no tempo, gerando "marcos legais estáveis para serem acompanhados pela população".

Junte-se a tais diretrizes governamentais a recente Lei de Acesso à Informação, de maio de 2012. De acordo com análise de Patrício e Silvestrin (2012), a Instrução Normativa n. 05/2011, publicada em 7 de junho de 2011, conceitua as ações de comunicação do Poder Executivo Federal, sendo que tais ações já estavam previstas no artigo $3^{\circ}$ do Decreto n. 7.379, de 1 de dezembro de 2010. Segundo os autores, o artigo prevê que as ações do Executivo Federal abranjam: "comunicação digital, comunicação pública, promoção, patrocínio, publicidade (classificada em de utilidade pública, institucional, mercadológica e legal), relações com a imprensa e relações públicas".

Entre as ações estratégicas de divulgação de informações pela Secom/PR estão: o programa de formadores de opinião, no qual 
jornalistas estrangeiros, intelectuais e outras pessoas consideradas influentes em termos de opinião pública mundial são convidados a conhecer de perto experiências brasileiras em vários campos (produtivo, social, ambiental, etc.); publicações; realização de seminários nacionais e internacionais, dentro e fora do país, para tratar de temáticas diversas de interesse do governo, inclusive sobre comunicação pública; uso de mídias digitais e sociais próprias, como o "Portal Brasil", twitter e facebook, entre outras.

Além disso, dentro do princípio da comunicação integrada, regularmente são realizadas reuniões com outros órgãos governamentais, especialmente com as assessorias de comunicação social ou de imprensa (embora não somente), para que se afinem os discursos, se compartilhem informações e se tracem ações conjuntas. A Área Internacional da Secom/PR, coordenada por um diplomata, costuma atuar muitas vezes em parceria com o Itamaraty/MRE e com a APEX (Agência Brasileira de Promoção de Exportações e Investimentos) para a divulgação do país no exterior.

Norteados pelos princípios da integração e da difusão é que os produtores de informações governamentais da Secom/PR são unânimes em afirmar que eles procuram dar visibilidade para ações positivas do governo, e não fazer propaganda política do governo, de governantes ou partidos, configurando o que se convencionou chamar de "chapa branca" 105 .

105 Para uma discussão sobre "comunicação chapa branca" e um ponto de vista "de dentro" da comunicação social durante o governo Lula da Silva, ver: Bucci (2008). Cabe esclarecer que este trabalho não se preocupa em verificar empiricamente se os discursos condizem com a realidade dos fatos. Antes, o que se pretende é apresentar a perspectiva da Secom/PR e de seus profissionais. 


\section{O"Brasil" e os "brasis"}

Com o título de "Por dentro do Brasil" (na versão inglesa, Brasil Insights Series), a Secom/PR produziu uma coletânea de livretos bilíngue contendo informações sobre "quem somos nós" na perspectiva econômica e política, tendo por base dados empíricos e numéricos, que são distribuídos como forma de divulgação do país dentro e fora do âmbito nacional.

A coletânea, que traz em sua capa uma espécie de mapa contendo o contorno do Brasil nas cores nacionais em destaque - como se fosse um corte de bandeira - e os perfis dos demais continentes em verde sob um fundo branco, traz os seguintes volumes: Ciência, Tecnologia e Inovação/Science, Technology and Innovation; Meio Ambiente/Environment; Eleições/Elections; Ambiente de Negócios/Business Environment; Combate ao Trabalho Análogo ao de Escravo/Fight Against Labor Analogous to Slavery; Sistema Financeiro/Financial System; Modernização da Gestão Pública/The Modernization of Public Management; Esportes/Sports; Energia/ Energy; Educação/Education.

Cada um deles representa um tema estratégico que de algum modo ajuda a construir uma percepção de quem é o Brasil no que se refere a parâmetros de "desenvolvimento real", de acordo com o diplomata da AI, Augusto Pestana, e uma jornalista da CDN/ Secom/PR, Maysa Provedello, ouvidos. Segundo eles, o Brasil apresentado não se baseia em uma divulgação "chapa branca", no sentido de ser uma representação fabricada artificialmente pelo governo brasileiro. Antes, seria um Brasil que "avançou" e cujo "avanço" deve ser divulgado.

Nas palavras do idealizador da AI da Secom/PR e ex-portavoz da Presidência da República no governo Dilma Roussef, o diplomata Rodrigo de Lima Baena Soares (em entrevista à autora 
em maio de 2011), trata-se de "modificar a percepção do Brasil no exterior, antes identificado apenas como uma terra de belas mulheres, do samba e do futebol". Para ele, "não há nenhum problema em ver o país dessa forma, o problema está em ver apenas isso" - é interessante observar que, há poucos meses, ele deixou a porta-voz da Presidência da República e passou a coordenar ações relativas às Olimpíadas de 2014.

Segundo a explicação do diplomata, a construção de uma percepção mais voltada para uma "identidade cultural brasileira" ficaria a cargo do setor cultural do Itamaraty, e de uma "identidade política e econômica" ficaria sob a responsabilidade da Secom/PR. Mas, conforme esclarece o coordenador da AI da Secom/PR, Augusto Pestana, "trabalhamos de uma forma muito integrada".

A construção da identidade internacional do Brasil, no exterior, é um tema tanto de reflexão teórica quanto serve como referencial para formulações de política externa. Para o ex-Ministro das Relações Exteriores, Celso Lafer (2009, p.19), a característica política que identifica o Brasil como um mediador externo "parte de uma visão da identidade coletiva, de um nós assinalador de especificidades. Entre estas especificidades, cabe destacar a localização geográfica no mundo, a experiência histórica, o código da língua e da cultura, os níveis e desenvolvimento e os dados de estratificação social”.

Na perspectiva adotada por Lafer, é interessante notar suas referências do que seria essa "identidade brasileira" identificando-a com o pensamento social brasileiro clássico: ele cita como referências de uma identidade nacional brasileira autores como Darcy Ribeiro, Sérgio Buarque de Holanda e Gilberto Freyre, ressaltando nosso caráter "de miscigenação, de flexibilidade, fruto de um amálgama de diferentes matrizes raciais e distintas tradições culturais".

Não é à toa que ao ser perguntado sobre que noção de "Brasil" estaria em jogo cotidianamente no desenvolvimento das atividades 
de divulgação das ações do país no exterior e da construção da percepção de uma opinião pública internacional favorável ao país em termos de "quem somos", o coordenador da AI/Secom/PR tenha respondido em uma frase: "somos um Brasil plural".

A amplitude da frase e dos sentidos que carrega do ponto de vista das possibilidades de seu uso e das definições que engendra correspondem antes a uma característica de resiliência política do que de uma percepção ingênua de "identidade nacional". Ainda que tomando emprestadas as especificidades culturais de que fala Lafer, declarações públicas de representantes do governo ressaltam um maior protagonismo brasileiro no cenário internacional.

Nesse sentido, se antes do Governo Lula da Silva (2003-2010) se tinha uma percepção política interna e externa em que a flexibilidade brasileira vinha sempre acompanhada de uma passividade política diante dos assuntos internacionais, passou-se a entender que ela agora estaria combinada a um maior protagonismo internacional.

Um exemplo que ressalta o caráter flexível, pacífico e plural brasileiro do ponto de vista das percepções externas aliado a um posicionamento mais protagônico foi o episódio da intermediação do Brasil para uma negociação entre Irã e Turquia relativa ao programa nuclear iraniano em 2010. Outro caso mais atual é o da realização da Conferência "Rio+20" que trata do desenvolvimento sustentável mundial, no Rio de Janeiro, em junho de 2012.

No caso da "Rio+20", a identificação de quem seríamos estaria atrelada ainda a uma construção de percepção de que "somos" um país que caminha em direção "ao desenvolvimento sustentável, e isso inclui o desenvolvimento ambiental, produtivo e social", segundo o coordenador da $\mathrm{AI} / \mathrm{Secom} / \mathrm{PR}$, em entrevista à autora em maio, um mês antes da conferência. Um dos modos de explicitar essa "nossa vocação" foi o convite a formadores de opinião pública 
e jornalistas estrangeiros (já comentado) para conhecerem experiências brasileiras bem-sucedidas nesse sentido. Assim, visitas a indústrias em São Paulo e a fazendas produtivas sustentáveis no Sul do país foram realizadas em 2012.

\section{Considerações finais}

O debate acadêmico e político sobre a noção de identidade apresenta entendimentos que englobam tanto a solidificação de seu conceito quanto o pressuposto de uma abstração radical que no limite significa a sua inexistência teórica ou prática. Mas, como nos lembram Bastos e Lopes (2011, p.13), "a questão da identidade tornou-se um dos grandes temas dos tempos em que vivemos" e ela se torna "uma indagação quando colocada sob suspeita".

A perspectiva adotada nesta pesquisa junto a Secom/PR é a de que a noção de identidade existe para os agentes que com ela trabalham cotidianamente ao construírem imagens e percepções de "Brasil", assim como eles utilizam o próprio termo "identidade" - e não "identificação", por exemplo. Diante disso, trabalha-se aqui como uma categoria nativa que expressa uma espécie de singularidade brasileira, mesmo que tal especificidade não seja considerada de um modo tão engessado ou sólido como a própria noção de identidade possa sugerir.

$\mathrm{O}$ entendimento do grupo pesquisado sobre o que seria a "identidade brasileira", para dentro ou para fora do país, é marcado pela resiliência que seus usos em contextos e situações concretas ou presumidas pedem politicamente. E nesse sentido, talvez a concepção em termos de práticas sociais e representacionais dos agentes governamentais se aproxime da própria concepção de Hall (2006) sobre o que seria uma identidade cultural na pós-modernidade: "formada e transformada continuamente em relação às formas pelas 
quais somos representados ou interpelados nos sistemas culturais que nos rodeiam" (p.13).

Desse modo, mesmo que o pressuposto de um caráter nacional clássico formulado por intelectuais brasileiros - que abrange traços culturais como flexibilidade, pacifismo, miscigenação e pluralidade - seja tido como referencial, a orientação governamental baseada na ideia de protagonismo político atualiza tais características em termos de intensidade e objetivos a serem cumpridos, assim como em relação aos interlocutores nacionais e internacionais do próprio governo brasileiro.

Em uma dimensão mais concreta, as informações divulgadas sobre o Brasil no exterior estão orientadas para a construção de uma percepção internacional de que o país está mais "desenvolvido" econômico, ambiental e socialmente em relação a períodos anteriores, segundo o discurso compartilhado de membros da Secom/PR.

Paralelamente, o governo vem investindo pesadamente na política de divulgação do país no Brasil e no exterior, tanto por meio da Lei de Acesso à Informação, quanto por meio da contratação da CDN que possui escritório em Washington e profissionais trabalhando diretamente na Secom/PR (em Brasilia), ou de investimentos na Empresa Brasileira de Comunicação que abrange a TV Brasil Internacional, por exemplo.

Além dessas ações, outras estratégias adotadas para melhorar as percepções do Brasil lá fora - e, portanto, construir um ambiente político internacional mais favorável - é criar situações em que os aspectos considerados positivos em relação a parâmetros internacionais possam ser dados a conhecer. Isso é feito por meio de sites governamentais, divulgação nos meios de comunicação domésticos e estrangeiros e mídias governamentais, convites realizados aos formadores de opinião mundiais para conhecer a "realidade brasileira". 
Ao trabalhar a comunicação pública nacional e internacional de modo integrado, em cima de diálogos estabelecidos entre a Secom/PR, os diversos ministérios e órgãos governamentais, além da iniciativa privada, o discurso político constrói o pressuposto identitário de um "Brasil Plural" aberto ao diálogo embora não subserviente. Se essa corresponde de fato à percepção da comunidade internacional sobre "quem somos" não é possível nem é a intenção deste trabalho dizer. No entanto, trata-se de uma concepção norteadora de políticas governamentais no campo da comunicação internacional e da política externa brasileira.

\section{Referências}

BASTOS, Liliana Cabral; LOPES, Luiz Paulo da Moita (orgs.). Introdução. In: . Estudos de identidade, entre saberes e práticas. Rio de Janeiro: Garamond, 2011.

BAUMAN, Zygmunt. Identidade. Rio de Janeiro: Jorge Zahar Ed., 2005.

BOURDIEU, Pierre. Ce que parler veut dire: l'économie des échanges linguistiques. Paris: Fayard, 1982.

. Sobre a televisão. Rio de Janeiro: Jorge Zahar Editor, 1997.

BUCCI, Eugênio. Em Brasília, 19 horas: a guerra entre a chapa -branca e o direito à informação no primeiro governo Lula. Rio de Janeiro: Record, 2008. 
CHAMPAGNE, Patrick. Faire l'opinion. Le Nouveau Jeu

Politique. Paris: Les Editions de Minuit, 1990.

EKECRANTZ, Jan. Espetáculos midiatizados e comunicações democráticas: entre a hegemonia global e a ação cívica. In: MAIA, Rousiley; CASTRO, Maria Céres Pimenta Spínola (orgs.). Mídia, esfera pública e identidades coletivas. Belo Horizonte: Editora UFMG, 2006.

FARIA, Carlos Aurélio Pimenta. Opinião pública e política externa: insulamento, politização e reforma na produção da política exterior do Brasil. Revista Brasileira de Política Internacional, v.51, n.2, p.80-97. 2008

LAFER, Celso. A identidade internacional do Brasil e a política externa brasileira. São Paulo: Perspectiva, 2009.

HALL, Stuart. A identidade cultural na pós-modernidade. 11.ed. Rio de Janeiro: DP\&A, 2006.

MANZUR, Tânia Maria P. Gomes. Opinião pública e política externa do Brasil do Império a João Goulart: um balanço historiográfico. Revista Brasileira de Política Internacional, v.42, n.1, p.30-61.1999.

MARTINS, Franklin de Souza. Ciclo de palestras: Comunicação Social. Brasília: Presidência da República/ Secretaria de Assuntos Estratégicos, Imprensa Nacional, 2010.

PATRÍCIO, Tássia Valente Viana Arouche; SILVESTRIN, Celsi Brönstrup. Comunicação no governo federal: análise da Instrução 
300 Normativa n. 05/2011 da Secretaria de Comunicação Social da Presidência da República. Revista Brasileira de Políticas de Comunicação, ed. 2, 2012. Disponível em: .....

SCOTTO, Maria Gabriela. As (difusas) fronteiras entre a política e o mercado: um estudo antropológico sobre marketing político, seus agentes, práticas e representações. PPGAS/Museu Nacional/UFRJ. Tese (Doutorado em Antropologia Social), Rio de Janeiro, 2003.

THOMPSON, John B. A mídia e a modernidade: uma teoria social da mídia. Petrópolis: Vozes, 1998.

WEBER, Maria Helena. Visibilidade e credibilidade. Tensões da comunicação política. In: MAIA, Rousiley; CASTRO, Maria Céres Pimenta Spínola (orgs.). Mídia, esfera pública e identidades coletivas. Belo Horizonte: Editora UFMG, 2006. 